Portland State University

PDXScholar

\title{
A National Research Project Revitalizes and Strengthens a SIG's Membership, Leadership, and the Quality of Research in the Field
}

\author{
Steven B. Mertens \\ University of Illinois \\ Vincent A. Anfara Jr. \\ University of Tennessee \\ Nancy Flowers \\ University of Illinois at Urbana-Champaign \\ Micki M. Caskey \\ Portland State University, caskeym@pdx.edu
}

Follow this and additional works at: https://pdxscholar.library.pdx.edu/ci_fac

Part of the Curriculum and Instruction Commons, and the Educational Assessment, Evaluation, and Research Commons

\section{Let us know how access to this document benefits you.}

\section{Citation Details}

Mertens, Steven B.; Anfara, Vincent A. Jr.; Flowers, Nancy; and Caskey, Micki M., "A National Research Project Revitalizes and Strengthens a SIG's Membership, Leadership, and the Quality of Research in the Field" (2011). Curriculum and Instruction Faculty Publications and Presentations. 5. https://pdxscholar.library.pdx.edu/ci_fac/5

This Post-Print is brought to you for free and open access. It has been accepted for inclusion in Curriculum and Instruction Faculty Publications and Presentations by an authorized administrator of PDXScholar. Please contact us if we can make this document more accessible: pdxscholar@pdx.edu. 


\section{A National Research Project Revitalizes and Strengthens a SIG's Membership, Leadership, and the Quality of Research in the Field}

Steven B. Mertens, Vincent A. Anfara, Jr., Nancy Flowers, and Micki M. Caskey

A recent moratorium has temporarily halted the creation of new Special Interest Groups (SIGs) in the American Educational Research Association. The AERA SIG Executive Committee, the official governance body that oversees approximately 160 SIGs, requested this moratorium, which was subsequently approved by AERA Council. The purpose of the moratorium is to allow the SIG Executive Committee to gather data that would facilitate a more critical examination of issues related to SIGs, including low membership numbers, leadership challenges, and specific membership needs addressed by SIGs. This article offers the Middle Level Education Research SIG (hereinafter MLER) as an example of a SIG that grappled with low membership from the mid-1990s to early 2000; suffered from a lack of leaders willing to invest the time and energy to revitalize, sustain, and expand the organization; and included members who were facing important issues related to the nature and scope of research in their field (e.g., the lack of a national database and large-scale studies to potentially influence policy and practice).

In 2003, the officers of the MLER surveyed its membership to ascertain research interests, potential activities, and future directions. Based on the results of that survey, the SIG's officers and council members developed and implemented a five-year strategic plan. The five components of the strategic plan were to

1. Become more active in advocacy work at local, state, and national levels;

2. Disseminate information on middle grades education to policy makers and others;

3. Gather information from SIG members about their expectations and participation in the SIG; 
4. Sponsor a symposium or summit to address a current and/or critical issue of middle grades education research; and

5. Sponsor and develop a "national" research project designed and implemented by the SIG membership.

During the past seven years, the MLER made significant gains in its membership by providing a variety of benefits and activities. While membership hovered around 20 to 30 in the late 1990s, the strategic plan provided the impetus for growth to approximately 180 members.

This article briefly describes and discusses the fifth component of the MLER strategic plan, the SIG's National Research Project on Common Planning Time. With this initiative the MLER offered its members an opportunity to participate in a national research project, combined with opportunities to present their research findings at national conferences and publish their results in a book series. Other AERA SIGs and divisions may benefit from the lessons learned as the MLER effectively revitalized its membership and leadership and contributed significantly to the quality of research in middle grades education.

\section{Origins of Common Planning Time Project}

In April 2006, Mertens (2006) presented a white paper, A Proposal for Establishing a National Middle Level Research Project, to the MLER officers and council members during AERA's annual meeting in San Francisco (see http://www.rmle.pdx.edu). The paper addressed the feasibility of MLER's engaging in a quasi-national research project, involving SIG members and addressing an issue critical to middle grades education research. In addition, it described the potential benefits to the SIG and its members, including (a) participation in a SIG-sponsored national project, (b) professional development for participant researchers, (c) fostering the development of the next generation of middle grades education researchers, (d) development of a 
quasi-national middle grades database, (e) participant access to the SIG middle grades database, and (f) opportunities for participants to disseminate research at national conferences and through publications.

Based on recommendations in the white paper, the SIG officers and council members voted to establish a steering committee to investigate the potential for a SIG-sponsored research project. In July 2006, the committee met for the first time in Chicago to discuss potential research topics, methodologies, and theoretical frameworks.

Subsequently, at the 2007 AERA annual meeting in Chicago, a subgroup of the steering committee proposed that the inaugural project for the new National Middle Grades Research Program focus on a critical and crucial component of successful middle schools: common planning time (CPT). A three-part rationale was set forth to support this proposal. First, a body of recent quantitative research exists which documents the benefits of CPT with regard to interdisciplinary team practices and student outcomes, including achievement scores. Second, very little qualitative research (specifically, research on what teachers do during CPT and their perceptions of school structures that facilitate or hinder CPT) examines the issue of CPT and its impact on teacher or student outcomes. Third, a majority of the MLER's members identify themselves as qualitative researchers. In light of these factors, it seemed feasible for the SIG to develop a qualitative research project focusing on CPT and addressing the issue of the quality and content of the CPT, not simply the quantity of minutes. Because the project was conceived as involving all MLER members, it had the potential to grow and lead to a quasi-national data set, similar to the National Education Longitudinal Study or the National Assessment of Educational Progress. 


\section{The CPT Project}

The CPT Project addresses five research questions related to common planning time:

1. What are teachers' understandings of CPT (e.g., regarding its purpose, goals, and vision)?

2. How do teachers use their CPT?

3. How are teachers prepared professionally to use CPT?

4. What are the perceived benefits of CPT?

5. What are the perceived barriers to CPT?

These research questions, along with a standard set of protocols, data collection instruments, required trainings for all participant researchers, and a common definition of CPT, guide the project.

All MLER members are eligible to participate in the CPT Project, but participants are required to attend a training session to learn about the project design, methodologies, protocols, and procedures prior to beginning their individual research. The training sessions provide professional development to SIG members regarding best practices in research methods, leadership development among SIG members, and networking opportunities. In addition to attending a training session, participant researchers adhere to a common set of expectations and responsibilities throughout their participation in the CPT Project, such as fidelity to the overall research design, use of the data collection instruments without modification, and ethical and responsible conduct as representatives of the MLER. These requirements help ensure that data are gathered in a consistent manner, are of the highest quality, and are appropriate for inclusion in a national database.

The CPT Project was implemented in two phases. Phase I involved a qualitative research design in which MLER participant researchers observed middle school team meetings on 
common planning time and conducted follow-up teacher interviews. Phase II involved the collection of quantitative data through an online teacher survey to supplement the rich qualitative data of Phase I. Data from Phase I can be matched to data from Phase II, enabling researchers to triangulate their findings and results.

\section{Phase I}

Phase I of the project was launched in November 2007. The project leaders developed the qualitative data collection instruments (i.e., the observation protocol and the teacher interview protocol) used in Phase I (Mertens, Anfara, Roney, \& Caskey, 2007). The observation protocol is used to record attendance at the CPT meeting, teachers' role on the team, the physical arrangement of the meeting space, use of an agenda to guide the meeting, duration of the meeting, and the specific activities/behaviors/topics that teachers engaged in during the meeting, as well as how long they engaged in each. To ensure the comparability of data across researchers, it was important that there be a shared definition of the activities/behaviors/topics studied as part of CPT meetings. For this reason, the observation protocol contained detailed descriptions of the activities/behaviors/topics to be recorded. The teacher interview protocol is a scripted document with an introduction, interview questions, and a concluding statement. The existing research literature supports the use of scripted protocols in social science research to help ensure the reliability of data collected across researchers (Poole \& Lamb, 1998; Sternberg, Lamb, Esplin, \& Baradaran, 1999). The interview questions focus on demographic information, teachers' understanding of CPT, use of CPT, professional preparation, and the perceived benefits of and barriers to CPT.

In Phase I, four training sessions were conducted (in Houston in 2007, New York in 2008, Chicago in 2008, and Denver in 2008) with nearly 60 SIG researchers participating. 
During the training sessions, project leaders provided an overview of the project, reviewed a step-by-step process for participating in the project, reviewed best practices for collecting qualitative data, and discussed observation and interviewing techniques with participants. Specific training topics included submission of an IRB (institutional review board) application, sample selection, contact/communication with schools, linking data sources (i.e., team meeting observations and teacher interviews), instruction on how to conduct the CPT observations and teacher interviews using the protocols, and procedures for submitting the data to the MLER. Each researcher was also provided with a training manual that contained all necessary documents, protocols, and information for participating in the project (Mertens, Anfara, et al., 2007). Phase I data collection was completed in the spring of 2010.

To date, the National Research Project on Common Planning Time has developed a database containing Phase I interview and observation data from 29 schools in 13 states, including interview data from 221 teachers and observation data from $81 \mathrm{CPT}$ meetings. As of June 2010, data in the database were made available to participating researchers in Phase I via a password-protected website.

\section{Phase II}

Phase II of the project began in November 2009 and will continue through December 2011. To date, two training sessions have been conducted (in Indianapolis in 2009 and Denver in 2010), for approximately 20 researchers. Additional Phase II training sessions are planned for 2011, both face-to-face and through an online module (which MLER members can access and view at their convenience). Phase II involves the collection of quantitative data concerning varying aspects of CPT through an online teacher survey. The SIG has partnered with the Center for Prevention Research and Development (CPRD) at the University of Illinois because the CPRD 
has extensive experience in quantitative survey design and data collection. The CPT Project leaders and the CPRD developed the teacher survey to collect large-scale survey data about CPT from middle grades teachers. Several constructs of the survey (e.g., team practices, quality of team life, and team decision making) had been developed previously by CPRD. These reliable and valid measures have been used by CPRD for more than 15 years to collect national-level data on the implementation of the recommendations articulated in Turning Points: Preparing American Youth for the 21st Century (Carnegie Council on Adolescent Development, 1989). Notably, CPRD conducted several validation studies on these constructs and presented the results at national conferences (Flowers, Hesson-McInnis, Bishop, \& Mertens, 2007; Mertens \& Flowers, 2003; Mertens, Flowers, Hesson-McInnis, \& Bishop, 2006, 2007). For Phase II of the CPT Project, CPRD has agreed to electronically post and manage the survey during data collection, process the quantitative data, and ultimately provide researchers with an SPSS file of their data.

Topics of the Phase II trainings include submission of an IRB application, sample selection, contact/communication with schools, linking data sources (i.e., Phase I data and Phase II data), acquisition of survey materials, and instructions on how to administer the survey. Researchers remit \$50 per school to participate in Phase II. This fee covers online Web survey development and setup, survey completion tracking, data cleaning, and the creation of data sets. Each researcher receives a Phase II training manual containing all necessary documents, protocols, and information for participating in the project (Flowers, Mertens, Anfara, \& Caskey, 2009). To date, Phase II data have been collected from 510 teachers in 23 schools across five states. These data will be added to the National Research Project on Common Planning Time database upon the completion of the Phase II data collection. 


\section{Accomplishments and Future Directions}

The CPT Project has grown well beyond the original expectations. Data for both Phase I and Phase II of the project have been collected from more than 35 schools in 17 states, involving nearly 80 MLER members in some capacity. SIG members participating in the project have been provided with opportunities to present research papers at the MLER sessions at AERA annual meetings. Beginning at the 2008 AERA meeting in New York (and subsequently in 2009 in San Diego and 2010 in Denver), the SIG has sponsored symposia dedicated to the CPT Project. In 2009, the CPT Project leaders were invited to present a session at the National Middle School Association's (NMSA) annual conference describing the project and preliminary results; NMSA extended another invitation for a follow-up presentation at its 2010 conference. The project leaders recently published an article in NMSA's Middle School Journal summarizing the research literature on common planning time and describing the SIG's CPT project (Mertens, Flowers, Anfara, \& Caskey, 2010). Project leaders are also working on a volume for the Handbook of Research in Middle Level Education series, focusing on the CPT Project with contributions from SIG members participating in the research project.

In October 2010, the National Forum to Accelerate Middle-Grades Reform invited the project team to present a paper at the forum's biennial meeting to describe and discuss the CPT Project and its potential for influencing national middle level education policy. In an effort to disseminate the projects' research findings, the project team is currently seeking funding to sponsor a conference focusing on the CPT Project. The proposed conference would convene SIG members who participated in the project so they might (a) share their research efforts, (b) 
become skilled in using the national database, and (c) work collaboratively to address the five project research questions.

\section{Lessons Learned}

Over the past decade, the MLER, like many other SIGs, has undergone ebbs and flows in its membership, leadership, and activities. Based on member input and interest, the SIG leadership implemented a national research project in hopes of expanding and fostering its membership, developing future leadership, and generating high-quality research in middle grades education. Since 2003, the MLER membership has remained relatively constant, at approximately 185 members. This research project has afforded MLER members with meaningful ways to connect with the SIG beyond attending the annual SIG business meeting at the AERA conference. When considering membership numbers, it is important to recall that the research focus of the SIG delimits the number of potential members and that many MLER members identify with other professional organizations that are more practitioner oriented. Although growth in membership would have been beneficial, it is noteworthy that the SIG's membership has remained constant, particularly in light of recent economic downturns and financial cutbacks at institutions of higher education.

The MLER has been successful in developing future leadership through the implementation of the CPT Project. SIG members who participated in Phase I of the project have been elected as SIG officers and council members, and SIG members participating in Phase II may similarly decide to become leaders within the SIG. The identification and development of future leaders is vital to the health of the organization; this lesson was learned in the mid-1990s when the MLER membership dropped below 30 members. Being an effective leader requires, 
among other qualities, willingness to invest much time and energy attending to the needs of the organization.

Finally, the SIG's recent activities have engaged members in purposeful research. Future plans include mining the national database developed by the CPT project (called the National Database on Common Planning Time) to analyze the data and publish research that addresses the current gaps in the middle grades literature. The CPT Project houses data from 14 states (and growing) across the United States which were collected using standardized protocols. The intent is for results of the various research studies generated from the database to provide the evidence and support needed to influence policy making related to middle grades programs and practices. In addition, SIG members have been given opportunities to publish results from their CPT project work in journals and handbooks that focus on middle grades education. These opportunities have been invaluable to assistant and associate professors working toward tenure and promotion at their institutions of higher education.

An unanticipated lesson learned from the development of a national research project was the powerful nature of collaboration. The project leaders—-researchers from geographically dispersed institutions - worked collaboratively for multiple years to develop, implement, and monitor the research. Building on their professional relationships within the SIG, they were able to articulate shared goals and make a commitment to the project. They progressed through three stages of collaboration: building commitment to collaboration, committing to collaboration, and sustaining commitment to collaboration (Kezar, 2005). Their group effort not only allowed them to realize their goals but also served as an example for SIG members.

The National Research Project on Common Planning Time has enabled the MLER to maintain a strong and stable membership base and has enabled its members to participate in a 
research initiative — one with opportunities to collect and analyze data, refine methodological skills, and present and publish research results for a national audience. The project leaders encourage other SIGs and divisions to consider similar activities, especially research projects, to build and sustain their membership, grow their leadership, and provide professional opportunities to their members.

\section{REFERENCES}

Carnegie Council on Adolescent Development. (1989). Turning points: Preparing American youth for the 21st century. New York: Carnegie Corporation of New York.

Flowers, N., Hesson-McInnis, M., Bishop, C., \& Mertens, S. B. (2007, April). School contextual factors and student outcomes: A validation study. In S. B. Mertens (Chair), The impact of middle grade structures, organizations, and practices on student outcomes: Moving toward a multivariate/multi-level model. Symposium conducted at the annual meeting of the American Educational Research Association, Chicago, IL.

Flowers, N., Mertens, S. B., Anfara, V. A., Jr., \& Caskey, M. M. (2009). Middle Level Education Research SIG, National Middle Grades Research Project. Common planning time training manual: Phase II. Washington, DC: Middle Level Education Research, a Special Interest Group of the American Educational Research Association.

Kezar, A. (2005). Redesigning for collaboration within higher education institutions: An exploration into the developmental process. Research in Higher Education, 46(7), 831860.

Mertens, S. B. (2006, March). A proposal for establishing a national middle level research project. White paper submitted to the Middle Level Education Research Special Interest 
Group of the American Educational Research Association. Available at http://www.rmle.pdx.edu

Mertens, S. B., Anfara, V. A., Jr., Roney, K., \& Caskey, M. M. (2007). National Middle Grades Research Project: Common planning time training manual. Washington, DC: Middle Level Education Research, a Special Interest Group of the American Educational Research Association.

Mertens, S. B., \& Flowers, N. (2003, April). The relationship between team and classroom practices and student achievement. Paper presented at the annual meeting of the American Educational Research Association, Chicago, IL.

Mertens, S. B., Flowers, N., Anfara, V. A., Jr., \& Caskey, M. M. (2010). What research says about common planning time. Middle School Journal, 41(5), 50-57.

Mertens, S. B., Flowers, N., Hesson-McInnis, M., \& Bishop, C. (2006, April). Middle grades teaching practices: A validation study. Paper presented at the annual meeting of the American Educational Research Association, San Francisco, CA.

Mertens, S. B., Flowers, N., Hesson-McInnis, M., \& Bishop, C. (2007, April). Development of a multivariate/multi-level model examining the impact of middle grades structures, organizations, and practices on student outcomes. In S. B. Mertens (Chair), The impact of middle grade structures, organizations, and practices on student outcomes: Moving toward a multivariate/multi-level model. Symposium conducted at the annual meeting of the American Educational Research Association, Chicago, IL.

Poole, D. A., \& Lamb, M. E. (1998). Investigative interview of children: A guide for helping professionals. Washington, DC: American Psychological Association. 
Sternberg, K. J., Lamb, M. E., Esplin, P. W., \& Baradaran, L. P. (1999). Using a scripted protocol in investigative interviews: A pilot study. Applied Developmental Science, 3(2), $70-76$. 